\title{
PLASMID-MEDIATED QUINOLONE RESISTANCE DETERMINANTS IN ENTEROBACTERIACEAE FROM URINE CLINICAL SAMPLES
}

\author{
Orsolya Szabó $^{1 *}$, DÁniel Gulyás ${ }^{1}$, NikOlett Szabó ${ }^{1}$, Katalin KristóF ${ }^{2}$, \\ BÉlA KOCSIS ${ }^{1}$ and DÓRA SZABÓ ${ }^{1}$ \\ ${ }^{1}$ Institute of Medical Microbiology, Semmelweis University, Budapest, Hungary \\ ${ }^{2}$ Clinical Microbiology Laboratory, Institute of Laboratory Medicine, Semmelweis \\ University, Budapest, Hungary
}

(Received: 10 September 2017; accepted: 13 December 2018)

Plasmid-mediated quinolone resistance (PMQR) determinants including, qnrA, $q n r B$, qnrC, qnrD, qnrS, aac(6')-Ib-cr, oqxAB, and qepA, were investigated in 214 Enterobacteriaceae strains from urine clinical samples. Antimicrobial susceptibility testing for ciprofloxacin, ceftriaxone, and imipenem was performed by broth microdilution method. All strains were screened for PMQR genes by PCR. Virulence determinants, namely afa, pap, pil, sfa/foc, and kpsMT of eight Escherichia coli strains proven positive for at least one qnr gene, were investigated by PCR. All of the eight investigated strains carried the pil gene, showing that $\mathrm{P}$ fimbria is a common virulence determinant among $q n r$ positive $E$. coli. Out of 214 tested strains, 38 yielded any PMQR determinant, altogether 45 genes were detected namely, 6 qnrA, 1 qnrB, 2 qnrD and $8 q n r S, 9 a a c\left(6^{\prime}\right)-I b-c r$, and $19 o q x A B$; however, neither qepA nor $q n r C$ were detected. Notably, 18 Klebsiella spp., harbored oqxAB, nine E. coli were positive for $q n r S$ and two Morganella morganii yielded qnrD resistance determinant. In this study, we demonstrated $17.7 \%$ prevalence of PMQR-positive Enterobacteriaceae and first reported qnrD-resistance determinant in Hungary. Altogether, 25 PMQR-positive strains were susceptible or low-level resistant to ciprofloxacin with minimum inhibitory concentration (MIC) between 0.06 and $1 \mathrm{mg} / \mathrm{L}$, suggesting that prevalence of PMQR determinants is underestimated and screening among clinical isolates exhibiting reduced susceptibility is necessary. Fluoroquinolone resistance breakpoints of Enterobacteriaceae were revised in 2017 by European Committee of Antimicrobial Susceptibility Testing indicating ciprofloxacin susceptibility only until $0.25 \mathrm{mg} / \mathrm{L}$ MIC value.

Keywords: Enterobacteriaceae, quinolone resistance, urinary tract infection

*Corresponding author; E-mail: orsolya910120@gmail.com 


\section{Introduction}

Plasmid-mediated quinolone resistance (PMQR) was first described in 1998 and was named as Qnr determinant [1]. Since then, several lineges of Qnr have been detected as transferable resistance mechanism, namely QnrA, QnrB, QnrC, QnrD, QnrE, QnrS, and QnrVC. To date, numerous alleles of qnr genes were identified and listed in www.lahey.com/qnrStudies homepage [2]. Besides Qnr determinants, aminoglycosid-acetyltranferase $\left(6^{\prime}\right)$-Ib-cr was also identified as a plasmid-coded quinolone resistance determinant [3]. Furthermore, QepA and OqxAB efflux pumps also belong to the transferable quinolone resistance mechanisms $[4,5]$. Each of the aforementioned resistance determinant confers reduced susceptibility and low-level quinolone resistance in Enterobacteriaceae, which is characterized by ciprofloxacin minimum inhibitory concentrations (MICs) higher than the wild-type phenotype $(0.06 \mathrm{mg} / \mathrm{L})$, and reaching the currently accepted resistance breakpoint $(0.5 \mathrm{mg} / \mathrm{L})$ by European Committee of Antimicrobial Suscpetibility Testing (EUCAST) issued in 2017 [1].

Since the discovery of PMQRs, a worldwide distribution of these determinants has been described in Enterobacteriaceae. The association of PMQRs with beta-lactamases and with various resistance mechanisms was reported from different countries [6]. Several plasmids and mobile genetic elements were described as carriers of PMQR genes and additional resistance determinants. Determinants of $q n r A$, $q n r B$, and $q n r S$ are widely disseminated among Enterobacteriaceae. Transferable plasmid coding qnrB19, bla KPC-3 $_{\text {ShH }-11}$, bla $_{\mathrm{TEM}-1}$, and $a a c\left(6^{\prime}\right)-I b$ was detected in Klebsiella pneumoniae [7]; qnrS1 and bla ${ }_{\mathrm{VIM}-1}$ coding conjugative plasmids were described in Klebsiella oxytoca [8]; qnrA1 and bla $_{\mathrm{VEB}}$ coding transferable plasmids in Enterobacter cloacae were detected [9]; plasmids coding for armA, qnrS1, aac $\left(6^{\prime}\right)-I b-c r, b l a_{\mathrm{CTX}-\mathrm{M}-15}, b l a_{\mathrm{TEM}-1}$, and bla $_{\mathrm{NDM}-1}$ were transferable from $K$. pneumoniae [10]; and conjugative plasmid

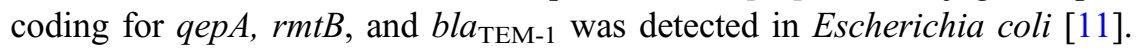

In the case of qnrC, it was first detected in Proteus mirabilis on a transferable plasmid; however, there have been no other reports released about this determinant [12].

First qnrD was detected in Salmonella spp., but later on, E. coli, P. mirabilis, Morganella morganii, and Providencia stuartii were all found to carry this resistance determinant [13-18]. Among clinical isolates, species of Proteae tribe commonly carry qnrD on small, non-transferable plasmids [16-18]. Most recently, QnrE1 has been detected in K. pneumoniae. Studies suggest that qnrE was most likely to be located in chromosome of Enterobacter spp. and mobilized by ISEcp1 to plasmids of $K$. pneumoniae [19, 20]. 


\section{Materials and Methods}

\section{Strains}

A total of 214 non-repetitive Enterobacteriaceae strains were collected between 2013 and 2014 at Semmelweis University, Clinical Microbiology Diagnostic Laboratory from urine clinical isolates, namely 99 E. coli, 36 Proteus spp., 32 Klebsiella spp., 20 Enterobacter spp., 15 Serratia spp., 6 Citrobacter spp., 5 Morganella sp., and 1 P. stuartii. Identification of strains was performed by matrix-assisted laser desorption ionization time of flight/mass spectrometry (Bruker Daltonik GmbH, Bremen, Germany). Each strain exhibited either susceptible, reduced suscpetible, or resistant fluoroquinolone phenotype based on routine diagnostic procedure carried out by disk diffusion method.

\section{Determination of MIC}

Ciprofloxacin, ceftriaxone, and imipenem MIC values of strains were determined by broth microdilution method by 96 -well microplates and interepreted after EUCAST documents issued in 2016 (www.eucast.org).

\section{PMQR gene detection}

Detection of PMQR genes was performed by PCR. DNA preparation was carried out from each tested strain as colonies were incubated at $100{ }^{\circ} \mathrm{C}$ for $15 \mathrm{~min}$ in a total volume of $0.5 \mathrm{ml}$ ultrapure distilled water (Millipore, Merck KGaA, Darmstadt, Germany) followed by centrifugation of cell suspension at $13,000 \mathrm{rpm}$ on $4{ }^{\circ} \mathrm{C}$. Each PCR mixture contained $1 \times$ PCR buffer $[10 \mathrm{mM}$ Tris- $\mathrm{HCl}$ (pH 8.3), $50 \mathrm{mM} \mathrm{KCl}$, $1.5 \mathrm{mM} \mathrm{MgCl}_{2}, 200 \mathrm{mM}$ each deoxynucleotide triphosphate, 20 pmol of each primer, and $1 \mathrm{U}$ of Taq polymerase (Sigma-Aldrich, St. Louis, MO, USA). Primers of this study are listed in Table I. Screening for $q n r A$, $q n r B$, and $q n r S$ was carried out by multiplex PCR with specific primer pairs of $q n r A-$, $q n r B-$, and $q n r S$ that amplified internal fragments with sizes of 516, 540, and $417 \mathrm{bp}$, respectively, PCR thermal profile was as follows: $10 \mathrm{~min}$ at $95^{\circ} \mathrm{C}$ and 32 cycles of amplification consisting of $45 \mathrm{~s}$ at $94{ }^{\circ} \mathrm{C}, 45 \mathrm{~s}$ at $53{ }^{\circ} \mathrm{C}$ and $1 \mathrm{~min}$ at $72{ }^{\circ} \mathrm{C}$, and an additional $10 \mathrm{~min}$ at $72{ }^{\circ} \mathrm{C}$ for the final extension [21-23]. Simplex PCR for detection of $q n r C$ and $q n r D$ with specific primers was performed with the following thermal profile $94{ }^{\circ} \mathrm{C}$ for $5 \mathrm{~min}, 94{ }^{\circ} \mathrm{C}$ for $1 \mathrm{~min}, 50{ }^{\circ} \mathrm{C}$ for $1 \mathrm{~min}$, and $72{ }^{\circ} \mathrm{C}$ for $1 \mathrm{~min}$ for 30 cycles; and $72^{\circ} \mathrm{C}$ for $10 \mathrm{~min}$, whereas $447 \mathrm{bp}$ of $q n r C$ and $550 \mathrm{bp}$ of $q n r D$ 
Table I. Primers used in the detection of PMQRs

\begin{tabular}{llc}
\hline Primer name & \multicolumn{1}{c}{ Sequence } & Reference \\
\hline qnrA fwd & ATTTCTCACGCCAGGATTTG & {$[3]$} \\
qnrA rev & GATCGGCAAAGGTTAGGTCA & \\
qnrB fwd & ATGACGCCATTACTGTATAA & {$[2]$} \\
qnrB fwd & GATCGCAATGTGTGAAGTT & \\
qnrS fwd & ACGACATTCGTCAACTGCAA & {$[3]$} \\
qnrS rev & TAAATTGGCACCCTGTAGGC & \\
qnrC fwd & GGGTTGTACATTTATTGAATC & {$[12]$} \\
qnrC rev & TCCACTTTACGAGGTTCT & \\
qnrD fwd & CGAGATCAATTTACGGGGAATA & {$[13]$} \\
qnrD rev & AACAAGCTGAAGCGCCTG & \\
qepA fwd & GCA GGT CCA GCAGCG GGT AG & {$[24]$} \\
qepA rev & CTT CCT GCC CGAGTA TCG TG & \\
oqxA fwd & CTCGGCGCGATGATGCT & {$[5]$} \\
oqxA rev & CCACTCTTCACGGGAGACGA & \\
oqxB fwd & TTCTCCCCCGGCGGGAAGTAC & \\
oqxB rev & CTCGGCCATTTTGGCGCGTA & \\
aac-(6')-Ib fwd & TTGCGATGCTCTATGAGTGGCTA & {$[25]$} \\
aac-(6')-Ib rev & CTCGAATGCCTGGCGTGTTT & \\
\hline
\end{tabular}

Note: PMQRs: plasmid-mediated quinolone resistances.

were amplified $[12,13]$. The $a a c\left(6^{\prime}\right)-I b$ gene was amplified by PCR with specific primers with following conditions: $94{ }^{\circ} \mathrm{C}$ for $45 \mathrm{~s}, 55^{\circ} \mathrm{C}$ for $45 \mathrm{~s}$, and $72{ }^{\circ} \mathrm{C}$ for $45 \mathrm{~s}$ for 34 cycles to produce a 482-bp product. All $a a c\left(6^{\prime}\right)-I b$ PCR positive amplicons were further analyzed by digestion with BstF5I (New England Biolabs, Ipswich, MA) to identify aac $\left(6^{\prime}\right)-I b-c r$, which lacks the BstF5I restriction site present in the wild-type gene [24]. A 199-bp fragment of qepA was amplified by PCR with qepA fwd and rev oligonucleotides wih following conditions: initial denaturation at $96^{\circ} \mathrm{C}$ for $1 \mathrm{~min}$, followed by 30 cycles of amplification at $96^{\circ} \mathrm{C}$ for $1 \mathrm{~min}$, annealing at $60^{\circ} \mathrm{C}$ for $1 \mathrm{~min}$, and extension at $72{ }^{\circ} \mathrm{C}$ for $1 \mathrm{~min}$. The final extension step was at $72{ }^{\circ} \mathrm{C}$ for $5 \mathrm{~min}$ [25]. The oqxAB resistance determinant was screened by PCR with specific oqxA fwd and rev and oqxB fwd and rev primers. PCR conditions for oqxA were $94{ }^{\circ} \mathrm{C}$ for $45 \mathrm{~s}, 57{ }^{\circ} \mathrm{C}$ for $45 \mathrm{~s}$, and $68{ }^{\circ} \mathrm{C}$ for $60 \mathrm{~s}$ with a cycle number of 34 , whereas in the case of $\operatorname{oqxB}$, the thermal profile was $94{ }^{\circ} \mathrm{C}$ for $45 \mathrm{~s}, 64^{\circ} \mathrm{C}$ for $45 \mathrm{~s}$, and $72^{\circ} \mathrm{C}$ for $60 \mathrm{~s}$ with a cycle number of 32 , whereas $392 \mathrm{bp}$ of $o q x A$ and $512 \mathrm{bp}$ of $o q x B$ were ampified [5]. DNA fragments were analyzed by electrophoresis in a $1.5 \%$ agarose gel (Sigma-Aldrich) at $120 \mathrm{~V}$ for $20 \mathrm{~min}$ in $1 \times$ TAE [ $40 \mathrm{mM}$ Tris- $\mathrm{HCl}$ (pH 8.3), $2 \mathrm{mM}$ acetate, $1 \mathrm{mM}$ EDTA]. Gel was stained by $0.05 \mathrm{mg} / \mathrm{L}$ Gelred dye (Biotum) and was evaluted by UV transilluminator. 
Detection of virulence determinants of $E$. coli

Tested virulence determinants of $E$. coli were the following: afimbrial adhesins ( $a f a), \mathrm{S}$ and F1C fimbiriae ( $s f a / f o c)$, pili associated with pyelonephritis (pap), $\mathrm{K}$-antigen ( $k p s M T$ ), and $\mathrm{P}$ fimbria ( $p i l)$. Detection of virulence determinants of eight $E$. coli strains, previously proven positive for at least one $q n r$ gene, was performed by PCR. Colonies of each tested E. coli strain were incubated in ultrapure distilled water (Millipore) at $100{ }^{\circ} \mathrm{C}$ for $10 \mathrm{~min}$ in a total volume of $500 \mu \mathrm{l}$ followed by centrifugation for $15 \mathrm{~min}$ at $13,000 \mathrm{rpm}$ at $4{ }^{\circ} \mathrm{C}$ temperature. After centrifugation, $200 \mathrm{ng}$ DNA template of $3 \mu \mathrm{l}$ of the supernatant was used in PCR along with the following components: 1.25 U Taq DNA polymerase (SigmaAldrich), $0.5 \mu \mathrm{M}$ of each virulence determinant oligonucleotide primer (Table II), $0.2 \mathrm{mM}$ dNTP mix (Sigma), $2.5 \mathrm{mM}$ buffer $\mathrm{Mg}^{2+}$ (Sigma), in $50 \mu \mathrm{l}$ total volume. Amplification was performed with the following protocol: 30 times of $94{ }^{\circ} \mathrm{C}$ for $1 \mathrm{~min}, 60{ }^{\circ} \mathrm{C}$ for $1 \mathrm{~min}$, and $72{ }^{\circ} \mathrm{C}$ for $1.5 \mathrm{~min}$, followed by an additional elongation at $72{ }^{\circ} \mathrm{C}$ for $7 \mathrm{~min}$. Amplicons were investigated by electrophoresis at $120 \mathrm{~V}$ for $25 \mathrm{~min}$ in a $1.5 \%$ agarose gel (Sigma-Aldrich) in a $1 \times$ TAE [ $40 \mathrm{mM}$ Tris- $\mathrm{HCl}$ (pH 8.3), $2 \mathrm{mM}$ acetate, and $1 \mathrm{mM}$ EDTA] buffer followed by $15 \mathrm{~min}$ of staining in Gelred dye (Biotum) and detected under UV transilluminator.

\section{Results}

Of 214 tested strains, 38 carried any of PMQRs alone or in combination and these represent $17.7 \%$ prevalence among Enterobacteriaceae. Altogether, 15 strains proved positive to any $q n r$ determinant and among them, eight $q n r S$, six

Table II. Primers used in detection of virulence determinants

\begin{tabular}{llc}
\hline Primer & \multicolumn{1}{c}{ Sequence } & Reference \\
\hline afa fwd & 5'-GCGGGCAGCAAACTGAAACTCTC-3' & {$[26]$} \\
afa rev & 5'-CATCAAGCTGTTTGTTCGTCCGCCG-3' & \\
sfa/foc fwd & 5'-CTCCGGAGAACTGGGTGCATCTTAC-3' & \\
sfa/foc rev & 5'-CGGAGGAGTAAATTACAAACCTGGCA-3' & \\
pap fwd & 5'-GCAACAGCAACGCTGGTTGCATCAT-3' & \\
pap rev & 5'-AGAGAGAGCCACTCTTATACGGACA-3' & \\
kpsMT fwd & 5'-CCATCGATACGATCATTGCACG-3' & {$[27]$} \\
kpsMT rev & 5'-ATTGCAAGGTAGTTCAGACTCA-3' & \\
pil fwd & 5'-CATTCGCCTGTAAAACCGCC-3' & {$[28]$} \\
pil rev & 5'-ATAACACGCCGCCATAAGCC-3' & \\
\hline
\end{tabular}

Note: afa: afimbrial adhesions; pap: pili associated with pyelonephritis; pil: $\mathrm{P}$ fimbria; sfa/foc: S and F1C fimbiriae; kpsMT: K-antigen. 
$q n r A$, two $q n r D$, and a single $q n r B$ were detected. Two $E$. coli strains carried both $q n r A$ and $q n r S$ determinants, although their ciprofloxacin MIC values were still at the wild-type phenotype $(0.06 \mathrm{mg} / \mathrm{L})$. Two $M$. morganii strains out of five were positive for $q n r D$, whereas on the other hand, four $P$. mirabilis strains carrried a qnrA determinant. Altogether, 19 strains (18 K. pneumoniae and an Enterobacter aerogenas) were positive for both oqxA and oqxB coding gene of efflux pump. Moreover, 20 strains (13 E. coli, 3 Proteus mirabilis, 3 Klebsiella spp., and $1 \mathrm{M}$. morganii) carried only oq $x A$, while 5 strains were positive only for oq $B$ (four Enterobacter spp. and a $K$. oxytoca). In contrast, neither qepA nor qnrC resistance determinants were found in this study. Among $23 a a c(6)-I b$, PCR positive strains BstF5I restriction enzyme analysis detected nine $a a c(6)-I b-c r$ variant, and these were carried by E. coli, M. morganii, Klebsiella spp., and Enterobacter spp. (Table III).

From 38 PMQR positive strains, 25 were under the ciprofloxacin resistance breakpoint of EUCAST issued in 2016 namely, 9 exhibited intermediate-resistant phenotype (MIC $0.5-1 \mathrm{mg} / \mathrm{L}), 13$ were still wild-type $(0.06 \mathrm{mg} / \mathrm{L})$, and 3 strains had $0.125 \mathrm{mg} / \mathrm{L}$ ciprofloxacin MIC value (Figure 1), but almost all of them were susceptible to ceftriaxone except one E. coli and two K. pneumoniae. Regarding imipenem MICs, all were found susceptible, only low-level imipenem resistance was common in all Proteus spp. and M. morganii strains (Table III).

Investigation of virulence determinants showed that pil gene, coding the $P$ fimbria virulence determinant was commonly carried by each tested strain. Other virulence factors varied among tested strains (Table IV).

\section{Discussion}

Our investigation found various PMQR determinants in a collection of 214 non-repetitive Enterobacteriaceae strains. Of $38 \mathrm{PMQR}$ positve strains, 9 showed intermediate fluoroquinolone resistance phenotype, 13 were still wild-type, and 3 had $0.125 \mathrm{mg} / \mathrm{L}$ ciprofloxacin MIC values, and all these 25 strains were still interpreted as susceptible after the EUCAST documents issued in 2016. EUCAST breakpoints in 2016 considered Enterobacteriaceae strains with MIC values under $0.5 \mathrm{mg} / \mathrm{L}$ as "susceptible," on the other hand, MIC over $1 \mathrm{mg} / \mathrm{L}$ as "resistant," and all in between as "intermediate" phenotype. Wild-type fluoroquinolone phenotype was MIC value $\leq 0.06 \mathrm{mg} / \mathrm{L}$. However, from January 1, 2017, these data were revised and declared $0.25 \mathrm{mg} / \mathrm{L}$ MIC value as the breakpoint of susceptibility, while resistance was set at $0.5 \mathrm{mg} / \mathrm{L}$. This change correlates well with our findings, as it emphasizes the possibility of the selection of resistant strains at $0.5 \mathrm{mg} / \mathrm{L} \mathrm{MIC}$ value, which may occur due to presence of PMQRs. 
Table III. Plasmid-mediated quinolone resistance (PMQR) determinant positive strains, with ciprofloxacin, ceftriaxone, and imipenem MIC values

\begin{tabular}{|c|c|c|c|c|c|}
\hline Number & Strain & PMQRs & Ciprofloxacin & Ceftriaxone & Imipenem \\
\hline 1 & E. coli 199 & $q n r B$ & 1.0 & 0.06 & 0.25 \\
\hline 2 & E. coli 193 & $q n r S$ & 0.5 & 0.06 & 0.25 \\
\hline 3 & E. coli 184 & $q n r S$ & 0.06 & 0.06 & 0.5 \\
\hline 4 & E. coli 180 & $q n r S$ & 0.125 & 0.06 & 0.25 \\
\hline 5 & E. coli 178 & $q n r S$ & 2.0 & 0.06 & 0.25 \\
\hline 6 & E. coli 177 & $q n r S$ & 0.06 & 0.06 & 0.25 \\
\hline 7 & E. coli 175 & $q n r S, a a c(6)-I b-c r$ & 32 & 128 & 0.25 \\
\hline 8 & E. coli 15 & $q n r A, q n r S$ & 0.06 & 0.06 & 0.125 \\
\hline 9 & E. coli 38 & $q n r A, q n r S$ & 0.06 & 0.06 & 0.125 \\
\hline 10 & M. morganii 10 & $q n r D$ & 2.0 & 0.06 & 4.0 \\
\hline 11 & M. morganii 71 & $q n r D, a a c(6)-I b-c r$ & 2.0 & 0.06 & 4.0 \\
\hline 12 & P. mirabilis 6 & $q n r A$ & 4.0 & 0.06 & 2.0 \\
\hline 13 & P. mirabilis 7 & $q n r A$ & 2.0 & 0.06 & 4.0 \\
\hline 14 & P. mirabilis 40 & $q n r A$ & 4.0 & 0.06 & 4.0 \\
\hline 15 & P. mirabilis 42 & $q n r A$ & 0.06 & 0.06 & 4.0 \\
\hline 16 & E. aerogenes & $o q x A B$ & 0.125 & 0.06 & 0.25 \\
\hline 17 & K. pneumoniae & $o q x A B$ & 8.0 & 0.25 & 0.25 \\
\hline 18 & K. pneumoniae & $o q x A B$ & 0.06 & 0.5 & 0.25 \\
\hline 19 & K. pneumoniae & $o q x A B$ & 128 & 0.06 & 0.5 \\
\hline 20 & K. pneumoniae & $o q x A B$ & 0.06 & 0.06 & 0.125 \\
\hline 21 & K. pneumoniae & $o q x A B$ & 0.06 & 0.06 & 0.125 \\
\hline 22 & K. pneumoniae & $o q x A B$ & 0.5 & 0.06 & 0.125 \\
\hline 23 & K. pneumoniae & $o q x A B$ & 0.06 & 0.06 & 0.125 \\
\hline 24 & K. pneumoniae & $o q x A B$ & 0.06 & 128 & 0.25 \\
\hline 25 & K. pneumoniae & $o q x A B$ & 0.125 & 0.5 & 0.25 \\
\hline 26 & K. pneumoniae & $o q x A B$ & 0.06 & 0.25 & 0.25 \\
\hline 27 & K. pneumoniae & $o q x A B$ & 1.0 & 1.0 & 0.25 \\
\hline 28 & K. pneumoniae & $o q x A B$ & 0.06 & 0.06 & 0.25 \\
\hline 29 & K. pneumoniae & $o q x A B$ & 16 & 0.125 & 0.25 \\
\hline 30 & K. pneumoniae & $o q x A B$ & 0.06 & 0.25 & 0.125 \\
\hline 31 & K. pneumoniae & $o q x A B$ & 0.5 & 1.0 & 0.125 \\
\hline 32 & K. pneumoniae & $o q x A B, a a c(6)-I b-c r$ & 1.0 & 128 & 0.25 \\
\hline 33 & K. pneumoniae & $o q x A B, a a c(6)-I b-c r$ & 2.0 & 0.5 & 0.25 \\
\hline 34 & K. pneumoniae & $o q x A B, a a c(6)-I b-c r$ & 4.0 & 0.25 & 0.5 \\
\hline 35 & K. oxytoca & $a a c(6)-I b-c r$ & 32 & 1.0 & 0.25 \\
\hline 36 & K. pneumoniae & $a a c(6)-I b-c r$ & 1.0 & 0.06 & 0.25 \\
\hline 37 & E. kobei & $a a c(6)-I b-c r$ & 1.0 & 0.125 & 0.5 \\
\hline 38 & E. cloacae & $a a c(6)-I b-c r$ & 1.0 & 0.25 & 0.25 \\
\hline
\end{tabular}

Note: All MIC values are in $(\mathrm{mg} / \mathrm{L})$.

Furthermore, it should also be noted that numerous strains carry PMQRs at the wild-type fluoroquinolone phenotype with ciprofloxacin MIC $0.06 \mathrm{mg} / \mathrm{L}$, in these cases, PMQR determinants remain latent that can be explained by lack of gene expression. 


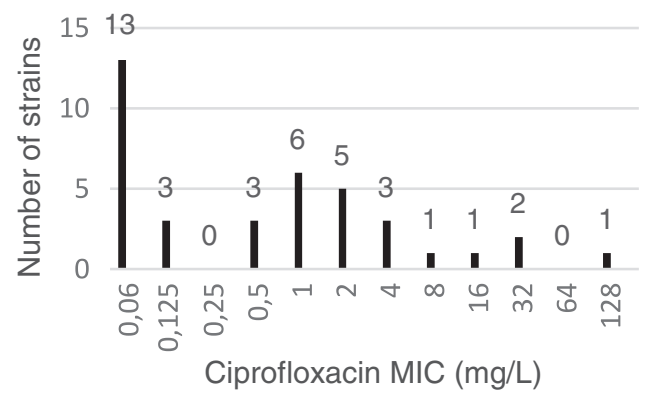

Figure 1. Ciprofloxacin minimum inhibitory concentration (MIC) distribution of $38 \mathrm{PMQR}$ positive strains

Table IV. Distribution of virulence determinants in the tested $E$. coli strains

\begin{tabular}{lccccc}
\hline Strain & afa & pap & pil & sfa/foc & kpsMT \\
\hline E.coli 15 & - & - & + & - & - \\
E.coli 38 & - & + & + & + & + \\
E.coli 177 & - & + & + & + & + \\
E.coli 178 & - & - & + & - & + \\
E.coli 180 & + & - & + & - & + \\
E.coli 184 & - & - & + & + & + \\
E.coli 193 & - & - & + & - & + \\
E.coli 199 & - & + & + & + & + \\
\hline
\end{tabular}

Note: afa: afimbrial adhesions; pap: pili associated with pyelonephritis; pil: P fimbria; sfa/foc: S and F1C fimbiriae; kpsMT: K-antigen.

Our data confirm that ciprofloxacin MIC values alone are not enough to detect resistance; therefore, detection of PMQRs, most importantly qnr genes, is to be conducted by molecular biological methods. According to this study, more thorough examination could be considered in case of strains exhibiting reduced susceptiblity and intermediate phenotype. In these cases, routine check on presence of PMQRs could be conducted to evalute possibility of selection of resistant strains. This study found $17.7 \%$ prevalence of PMQR-positive Enterobacteriaceae from urine clinical sample and this is the first report of qnrD resistance determinant in Hungary. Earlier, investigation from Hungary showed extended-spectrum beta-lactamase (ESBL)-producing E. coli and Klebsiella spp., with $q n r A, q n r B, q n r S$, and $a a c(6)-I b-c r$ [29, 30]. Although we did not investigate the correlation of PMQRs in ESBL-producing strains, but based on our results, we can say that there is no strong correlation, as we found a total 38 strains being PMQR positive, but among them, only three showed resistance to third generation of cefalosporin. 
According to international data, the prevalence of PMQR genes, $q n r A$, qnrB, $q n r S, a a c\left(6^{\prime}\right)-I b-c r$, and $q e p A$ is associated with ESBLs, but actual prevalence of $q n r C$ is unknown; however, some data are released about $q n r D[6,17,30]$.

In this study, we report the first detection of $q n r D$ determinant in Hungary, which was found in two M. morganii strains that represent around $1 \%$ prevalence in Enterobacteriaceae and $40 \%$ of M. morganii. These data are in good correlation with international data, which demonstrated $q n r D$ determinant in clinical isolates among species of Proteaee tribe (Proteus spp., Providencia spp., and M. morganii) [16-18]. Our results show that $\mathrm{P}$ fimbria is a common virulence determinant among qnr-positive $E$. coli causing urinary tract infections.

\section{Acknowledgements}

The authors would like to thank Giuseppe Cornaglia (Verona, Italy) for sending us qnrA1, qnrB1, qnrC, qnrD1, and qnrSl control strains. This study was financially supported by OTKA Hungarian Scientific Fund, grant number: 108481.

\section{Conflict of Interest}

The authors declare no competing interests.

\section{References}

1. Martinez-Martinez, L., Pascual, A., Jacoby, G.: Quinolone resistance from transferable plasmid. Lancet 351, 797-799 (1998).

2. Jacoby, G., Cattoir, V., Hooper, D., Martinez-Martinez, L., Nordmann, P., Pascual, A., Poirel, L., Wang, M.: qnr gene nomenclature. Antimicrob Agents Chemother 52, 2297 2299 (2008).

3. Robicsek, A., Strahilevitz, J., Jacoby, G. A., Macielag, M., Abbanat, D., Park, C. H., Bush, K., Hooper, D. C.: Fluoroquinolone modifying enzyme: A new adaptation of a common aminoglycoside acetyltransferase. Nature 12, 83-88 (2006).

4. Yamane, K., Wachino, J. I., Suzuka, S., Kimura, K., Shibata, N., Kato, H., Shibayama, K., Konda, T., Arakawa, Y.: New plasmid medaited fluoroquinolone efflux pump, Qep A, found in an Escherichia coli clinical isolate. Antimicrob Agents Chemother 51, 3354-3360 (2007).

5. Kim, H. B., Wang, M., Park, C. H., Kim, E. C., Jacoby, G., Hooper, D. C.: oqxAB encoding a multidrug efflux pump in human clinical isolates of Enterobacteriaceae. Antimicrob Agents Chemother 53, 3582-3584 (2009).

6. Rodriguez-Martinez, J. M., Cano, M. E., Velasco, C., Martinez-Martinez, L., Pascual, A.: Plasmid-mediated quinolone resistance: An update. J Infect Chemother 17, 149-182 (2011). 
7. Endimiani, A., Carias, L. L., Hujer, A. M., Bethel, C. R., Hujer, K. M., Perez, F., Hutton, R. A., Fox, W. R., Hall, G. S., Jacobs, M. R., Paterson, D. L., Rice, L. B., Jenkins, S. G., Tenover, F. C., Bonomo, R. A.: Presence of plasmid-mediated quinolone resistance in Klebsiella pneumoniae isolates possessing bla $\mathrm{K}_{\mathrm{KPC}}$ in the United States. Antimicrob Agents Chemother 52, 2680-2682 (2008).

8. Carattoli, A., Aschbacher, R., March, A., Larcher, C., Livermoor, D. M., Woodford, N.: Complete nucleotide sequence of the IncN plasmid pKOX105 encoding VIM-1, QnrS1 and SHV-12 proteins in Enterobacteriaceae from Bolzano, Italy compared with IncN plasmids encoding KPC enzymes in the USA. J Antimicrob Chemother 65, 2070-2075 (2010).

9. Poirel, L., Van de Loo, M., Mammeri, H., Nordmann, P.: Association of plasmid-mediated quinolone resistance with extended-spectrum beta-lactamase VEB-1. Antimicrob Agents Chemother 49, 3091-3094 (2005).

10. Wei, D. D., Wan, L. G., Yu, Y., Xu, Q. F., Deng, Q., Cao, X. W., Liu, Y.: Characterization of extended-spectrum beta-lactamase, carbapenemase and plasmid quinolone determinants in Klebsiella pneumoniae isolates carrying distinct types of 16s rRNA methylase genes and their association with mobile genetic elements. Microbial Drug Resistance 21, 186-193 (2015).

11. Perichon, B., Bogaerts, P., Lambert, T., Frangeul, L., Courvalin, P., Galimand, M.: Sequence of conjugative plasmid pIP1206 mediating resistance to aminoglycosides by 16s rRNA methylation and to hydrophilic fluoroquinolones by efflux. Antimicrob Agents Chemother 52, 2581-2592 (2008).

12. Wang, M., Guo, Q., Xu, X., Wang, X., Ye, X., Wu, S., Hooper, D. C., Wang, M.: New plasmid-mediated quinolone resistance gene, qnrC, found in a clinical isolate of Proteus mirabilis. Antimicrob Agents Chemother 53, 1892-1897 (2009).

13. Cavaco, L. M., Hasman, H., Xia, S., Aarestrup, F. M.: qnrD, a novel gene conferring transferable quinolone resistance in Salmonella enterica serovar Kentucky and Bovismorbificans strains of human origin. Antimicrob Agents Chemother 53, 603-608 (2009).

14. Veldman, K., Cavaco, L. M., Mevius, D., Battisti, A., Franco, A., Botteldoorn, N., Bruneau, M., Perrin-Guyomard, A., Cerny, T., de Frutos Escobar, C., Guerra, B., Schroeter, A., Guitterez, M., Hopkins, K., Myllyniemi, A. L., Sunde, M., Wasyl, D., Aarestrup, F. M.: International collaborative study on the occurence of plasmid-medaited quinolone resisitance in Salmonella enterica and Escherichia coli isolated from animals, humans food and the environment in 13 European countries. J Antimicrob Chemother 66, 1278-1286 (2011).

15. Zhang, J., Chen, Z., Chen, S., Deng, Y., Liu, Y., Tian, W., Huang, X., Wu, C., Sun, Y., Sun, Y., Zeng, Z., Liu, J. H.: Prevalence and dissemination of oqxAB in Escherichia coli isolates from animals, farmworkers and the environment. Antimicrob Agents Chemother 54, 4219-4224 (2014).

16. Mazzariol, A., Kocsis, B., Koncan, R., Kocsis, E., Lanzafame, P., Cornaglia, G.: Description and plasmid characterization of qnrD determinants in Proteus mirabilis and Morganella morganii. Clin Microbiol Infect 18, E46-E48 (2012).

17. Guillard, T., Grillon, A., de Champs, C., Cartier, C., Madoux, J., Berçot, B., Lebreil, A. L., Lozniewski, A., Riahi, J., Vernet-Garnier, V., Cambau, E.: Mobile insertion cassette elements found in small non-transmissible plasmids in Proteeae may explain qnrD mobilization. PLoS One 9, e87801 (2014).

18. Guillard, T., Cambau, E., Neuwirth, C., Nenninger, T., Mbadi, A., Brasme, L., VernetGarnier, V., Bajolet, O., de Champs, C.: Description of a 2, 683-base-pair plasmid 
containing qnrD in two Providencia rettgeri isolates. Antimicrob Agents Chemother 56, 565-568 (2012).

19. Albornoz, E., Tijet, N., De Belder, D., Gomez, S., Martino, F., Corso, A., Melano, R. G., Petroni, A.: qnrE1, a member of a new family of plasmid-located quinolone resistance genes, originated from the chromosome of Enterobacter species. Antimicrob Agents Chemother 61, e02555-16 (2017).

20. Cunha, M. P. V., Davies, Y. M., Cerdeira, L., Dropa, M., Lincopan, N., Knöbl, T.: Complete DNA sequence of an IncM1 plasmid bearing the novel qnrE1 plasmid-mediated quinolone resistance variant and bla CTX-M-8 from Klebsiella pneumoniae sequence type 147. Antimicrob Agents Chemother 61, e00592-17 (2017).

21. Cattoir, V., Poirel, L., Rotimi, V., Soussy, C. J., Nordmann, P.: Multiplex PCR for detection of plasmid-mediated quinolone resistance qnr genes in ESBL-producing enterobacterial isolates. J Antimicrob Chemother 60, 394-397 (2007).

22. Robicsek, A., Strahilevitz, J., Sahm, D. F., Jacoby, G. A., Hooper, D. C.: qnr prevalence in ceftazidime-resistant Enterobacteriaceae isolates from the United States. Antimicrob Agents Chemother 50, 2872-2874 (2006).

23. Jacoby, G. A., Walsh, K. E., Mills, D. M., Walker, V. J., Oh, H., Robicsek, A., Hooper, D.: qnrB, another plasmid-mediated gene for quinolone resistance. Antimicrob Agents Chemother 50, 1178-1182 (2006).

24. Yamane, K., Wachino, J. I., Suzuki, S., Arakawa, Y.: Plasmid-mediated qepA gene among Escherichia coli clinical isolates in Japan. Antimicrob Agents Chemother 52, 1564-1566 (2008).

25. Park, C. H., Robicsek, A., Jacoby, G. A., Sahm, D., Hooper, D. C.: Prevalence in the United States of aac $\left(6^{\prime}\right)-\mathrm{Ib}-\mathrm{cr}$ encoding a ciprofloxacin-modifying enzyme. Antimicrob Agents Chemother 50, 3953-3955 (2006).

26. Yamamoto, S., Terai, A., Yuri, K., Kurazono, H., Takeda, Y., Yoshida, O.: Detection of urovirulence factors in Escherichia coli by multiplex polymerase chain reaction. FEMS Immunol Med Microbiol 12, 85-90 (1995).

27. Kanamaru, S., Kurazono, H., Ishitoya, S., Terai, A., Habuchi, T., Nakano, M., Ogawa, O., Yamamoto, S.: Distribution and genetic association of putative uropathogenic virulence factors iroN, iha, kpsMT, ompT and usp in Escherichia coli isolated from urinary tract infections in Japan. J Urol 170, 2490-2493 (2003).

28. Tseng, C. C., Huang, J. J., Ko, W. C., Yan, J. J., Wu, J. J.: Decreased predominance of papG class 2 allele in Escherichia coli strains isolated from adults with acute pyelonephritis and urinary tract abnormalities. J Urol 166, 1643-1646 (2001).

29. Szabo, D., Kocsis, B., Rókusz, L., Szentandrássy, J., Katona, K., Kristof, K., Nagy, K.: First detection of plasmid-mediated quinolone resistance determinants qnrA, qnrB, qnrS and aac (6)-Ib-cr in extended-spectrum beta-lactamse (ESBL)-producing Enterobacteriaceae in Budapest, Hungary. J Antimicrob Chemother 62, 630-632 (2008).

30. Domokos, J., Kristóf, K., Szabó, D.: Plasmid-mediated quinolone resistance among extended-spectrum beta-lactamase producing Enterobacteriaceae from bloodstream infections. Acta Microbiol Immunol Hung 63, 313-323 (2016). 